\title{
Qualitative and Quantitative Assay of Hydroxycinnamates of Prunus Spinosa L.
}

\author{
Sergey Kondrashev', Nadezhda Nesterova ${ }^{3}$, Alexey Luzin', Vitaliy Kochanov', Anna Luzina ${ }^{4}$, Alexey \\ Matyushin ${ }^{2, *}$
}

Sergey Kondrashev', Nadezhda Nesterova ${ }^{3}$, Alexey Luzin', Vitaliy Kochanov ${ }^{1}$, Anna Luzina ${ }^{4}$, Alexey Matyushin ${ }^{2, *}$

'Department of Chemistry, Sechenov First Moscow State Medical University, Moscow, RUSSIAN FEDERATION.

${ }^{2}$ Department of Analytical and Forensic Toxicology, Sechenov First Moscow State Medical University, Moscow, RUSSIAN FEDERATION.

${ }^{3}$ Department of Natural Science in Pharmacy, Sechenov First Moscow State Medical University, Moscow, RUSSIAN FEDERATION ${ }^{4}$ Department of Dentistry, Sechenov First Moscow State Medical University, Moscow, RUSSIAN FEDERATION.

\section{Correspondence}

\section{Alexey Matyushin}

Sechenov First Moscow State Medical University, 8, Trubetskaya st., Moscow, 119991, RUSSIAN FEDERATION.

Phone no: +7 906-705-75-52

E-mail: matyushin@sechenov.ru History

- Submission Date: 06-10-2019;

- Review completed: 16-10-2019;

- Accepted Date: 30-10-2019.

DOI : 10.5530/pj.2020.12.23

Article Available online

http://www.phcogj.com/v12/i1

\section{Copyright}

(C) 2020 Phcogi.Com. This is an openaccess article distributed under the term of the Creative Commons Attribution 4.0 International license.

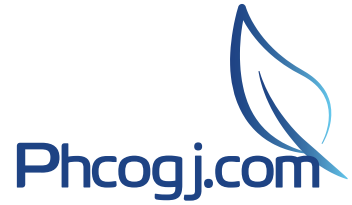

\begin{abstract}
Background: Blackthorn (Prunus spinosa L.) is a plant commonly found in the Russian Federation on the roadsides, forest margins, and meadows. Despite lack of recognition by the official medicine, blackthorn fruits possess antioxidant properties and are used in homeopathic preparations. They may also demonstrate antibacterial and anticancer potential due to hydroxycinnamic acids. The aim of present study was to identify and assay hydroxycinnamates in fruits of $P$. spinosa cultivated in Moscow Region. Materials and Methods: Fresh and dried fruits of $P$. spinosa, gathered from plants cultivated in Moscow Region in the harvest maturity stage, were used in the study. Qualitative composition of hydroxycinnamic acids was assessed by high performance liquid chromatography, using reversed phase C18 column. Total hydroxycinnamic acids (THA) content was assessed spectrophotometrically. Results: Similar chromatographic profiles were obtained for both fresh and dried blackthorn fruits, the two most abundant compounds being epicatechin $(2.91 \%)$ and chicoric acid $(2.90 \%)$. Fruits gathered in Chekhovsky District had lower content of hydroxycinnamates $(0.798 \pm 0.89)$ than those coming from Klinsky District $(0.886 \pm 0.92)$. However, the THA content in dried fruits grown in both districts was found to be similar $(0.540 \pm 0.71$ and $0.557 \pm 0.74$, respectively). Conclusions: It can be concluded that blackthorn fruits can be considered as a source of hydroxycinnamic acids, as both fresh and dried fruits contain at least eleven hydroxycinnamates. It was found that the dried fruits have similar content of hydroxycinnamic acids, independently of their origin. Future research should be aimed at drying method optimization.

Key Words: Blackthorn, Herbal raw material, HPLC, Hydroxycinnamic acids, Prunus Spinosa L., Spectrophotometry.
\end{abstract}

\section{INTRODUCTION}

Blackthorn (Prunus Spinosa L., P. stepposa Kotov) is a woody plant or shrub belonging to the Prunus genus of the Rosaceae family. In the Russian Federation it is commonly found on the roadsides, forest margins, meadows, and on the slopes of mountains and hills. ${ }^{1}$ Leaves and fruits of blackthorn are used in medicine since ancient times: in De Medicina, a medical treatise written by Roman physician Aulus Cornelius Celsus in the $1^{\text {st }}$ Century $\mathrm{AD}$, its fruits are mentioned numerous times as a remedy for gastrointestinal tract diseases, intertrigo, skin lesions, and wounds. ${ }^{2}$ Hippocrates of Kos recognized different kinds of P. spinosa as part of a healthy diet, which fitted his famous concept "Let food be thy medicine, and let medicine be thy food". Flowers, fruits, and leaves of blackthorn were used by Claudius Galenus and Pedanius Dioscorides. A separate chapter of The Canon of Medicine by Abu Ali ibn Sino was devoted to plums, including blackthorn. Ibn Sino stated different characteristics of fruits, noting that they help to make bile flow and strengthens the stomach, and described how to obtain and use blackthorn gum, which was thought to be helpful in crushing gallstones. ${ }^{3}$ In Russian traditional medicine blackthorn fruits decoction was prescribed to treat poisoning and later - for women suffering from gestational toxicosis.
With the advance of synthetic drugs $P$. spinosa was almost forgotten and is currently not recognized by modern regulatory documentation as herbal raw material; it is mentioned only in the "Nomenclature of single-component homeopathic medicines approved in the Russian Federation" listed in the Annex to the Order of the Ministry of Health and Medical Industry No. 335 dated 29.11.1995. However, recent studies have drawn attention of scientists to blackthorn fruits as they contain numerous biologically active substances that demonstrate wide range of pharmacological activities.

For example, phytochemical analysis of $P$. spinosa fruits gathered in Krasnoyarsk Krai, Russia, revealed presence of sugars (more than 7\%), flavonoids (up to $5 \%$ ), extractives (over $12 \%$ ), allowing authors to consider blackthorn as a prospective raw material not only for food industry, but also for herbal drug development and manufacturing. ${ }^{4}$ Blackthorn fruits also contain antioxidants, thus making them one of the possible means to fight oxidative stress - a key factor in ageing pathogenesis. ${ }^{5}$ Chromatographic analysis revealed presence of phytosterols in various aerial parts of blackthorn: $\beta$-sitosterol - in fruits, leaves, and flowers, 3-O- $\beta$-D-glucopyranoside, $\gamma$-sitosterol, stigmasterol - in flowers. ${ }^{6}$ Safonova et al. (2011) showed that leaves and fruits of P. spinosa have similar micro- and macroelemental composition, but the ratio between certain chemical elements varies.

Cite this article: Kondrashev S, Nesterova N, Luzin A, Kochanov V, Luzina A, Matyushin A Qualitative and Quantitative Assay of Hydroxycinnamates of Prunus Spinosa L. Pharmacog J. 2020;12(1):157-61. 
The study by Kumarasamy et al. (2004) described antibacterial and antiphage activity of blackthorn fruit juice. ${ }^{8}$ These findings suggest that blackthorn remains yet another prospective, but largely unstudied source of beneficial active substances. No study to date has revealed full therapeutic potential of blackthorn fruits in terms of their chemical composition.

Hydroxycinnamic acids are nonflavonoid phenols - prevalent plant phenolic acids that are generally derived from cinnamic acid. Some of them (caffeic, ferulic, p-coumaric) demonstrate antibacterial activity against widespread pathogens, such as Escherichia coli, Staphylococcus aureus, and Bacillus cereus at different $\mathrm{pH},{ }^{9}$ whereas others were found to be effective in in vitro inhibition of low-density lipoprotein oxidation. ${ }^{10}$ They possess strong antioxidant activity due to their ability to scavenge hydroxyl radicals, peroxyl radicals, and other radical species. ${ }^{11}$ Moreover, hydroxycinnamic acids demonstrate antigenotoxic ${ }^{12}$ and even anticancer properties. ${ }^{13}$ Therefore, the aim of our study was to identify and assay hydroxycinnamates in fruits of $P$. spinosa, widely cultivated in Moscow Region.

\section{MATERIALS AND METHODS}

Fresh and isothermally dried fruits of P. spinosa, gathered from plants cultivated in Moscow Region in the harvest maturity stage, were used in the study. Average sample was pooled from 20-30 fruits obtained from the middle parts of at least three tree crowns, then divided into two parts: one was used immediately after gathering, the other was dried.

All reagents used in the study were of analytical grade.

Qualitative analysis of biologically active substances was performed using aqueous alcohol solution, prepared in the following manner: a $5.0 \mathrm{~g}$ sample was ground, then placed in a round bottom flask, $50 \mathrm{ml}$ of $50 \%$ alcohol were added, the flask was attached to a reflux condenser and heated on a water bath for $30 \mathrm{~min}$. After that the solution was quantitatively transferred into a $50 \mathrm{ml}$ volumetric flask and diluted to volume with $50 \%$ alcohol. The flask was placed into an ultrasonic bath for 5 minutes, then $1 \mathrm{ml}$ of the sonicated solution was centrifugated at 14000 RPM for 10 minutes. The supernatant was transferred into a chromatographic vial and analyzed using Gilson (Gilson, France) high performance liquid chromatography (HPLC) system consisting of degasser, pump, thermostated autosampler (samples temperature - 15 ${ }^{\circ} \mathrm{C}$ ), diode-array detector, and thermostated chromatographic column $(250 \times 4.6 \mathrm{~mm}, 5 \mu \mathrm{m}$, Hypersil C18(2)). HPLC conditions were as follows:

Mobile phase: trifluoroacetic acid $(\mathrm{pH}=2.5) /$ acetonitrile

Flow rate: $1.0 \mathrm{ml} / \mathrm{min}$

Detection: UV, $\lambda=330 \mathrm{~nm}$
Injection volume: $20 \mu \mathrm{l}$

Total hydroxycinnamic acids (THA) content in blackthorn fruits was assayed using spectrophotometric method and expressed as chlorogenic acid. Absorption spectrum of chlorogenic acid reference standard (Sigma-Aldrich, USA) in 70\% alcohol demonstrated peak absorbance at $330 \mathrm{~nm}$ and a characteristic shoulder at $300 \mathrm{~nm}$, and was found to be matching the absorption spectra of aqueous alcoholic extracts from fresh and dried fruits of P. spinosa.

About $2 \mathrm{~g}$ of fruits, accurately weighed and ground (passing through No. 10 mesh sieve), were placed into a $200 \mathrm{ml}$ volumetric flask and $70 \mathrm{ml}$ of distilled water were added. The flask was attached to a reflux condenser and heated on a water bath for 15 minutes. Extraction was performed three times. The extracts were cooled at room temperature, filtered through a paper filter, combined, and quantitatively transferred into another $200 \mathrm{ml}$ volumetric flask. The solution was diluted to volume with distilled water and $1 \mathrm{ml}$ aliquot was transferred into a $50 \mathrm{ml}$ volumetric flask, and then diluted to volume with $20 \%$ alcohol. Absorbance was measured at characteristic wavelength of $330 \mathrm{~nm} .{ }^{9}$ Aqueous alcohol (20\%) was used as reference solution.

THA content (X, \%), expressed as chlorogenic acid, was calculated using the following formula:

$\mathrm{X}=\frac{\mathrm{A}_{\mathrm{x}} \times 200 \times 50 \times 100}{\mathrm{E}_{1 \mathrm{~cm}}^{1 \%} \times m \times V_{a} \times(100-W)}$,

where Ax - absorbance of test solution;

$\mathrm{E}_{1 \mathrm{~cm}}^{1 \%}$ - specific absorbance of chlorogenic acid at $330 \mathrm{~nm}$, equals to 507; $\mathrm{m}$ - mass of ground fruits, $\mathrm{g}$;

$V_{a}$ - aliquot volume, $\mathrm{ml}$

$\mathrm{W}$ - moisture content, \%.

Statistical analysis was performed according to the State Pharmacopeia's requirements (General Monograph 42-0111-09 "Statistical analysis of results of chemical experiments").

\section{RESULTS AND DISCUSSION}

Chromatographic analysis of alcoholic extracts, prepared from blackthorn fruits at various vegetative stages, demonstrated their identity in terms of biologically active substances qualitative composition (Figure 1 and Table 1).

Following statistical analysis of five parallel experiment results it was found that total hydroxycinnamic acids content in $P$. spinosa fruits, expressed as chlorogenic acid, was higher in fresh fruits than in dried ones (Table 2).

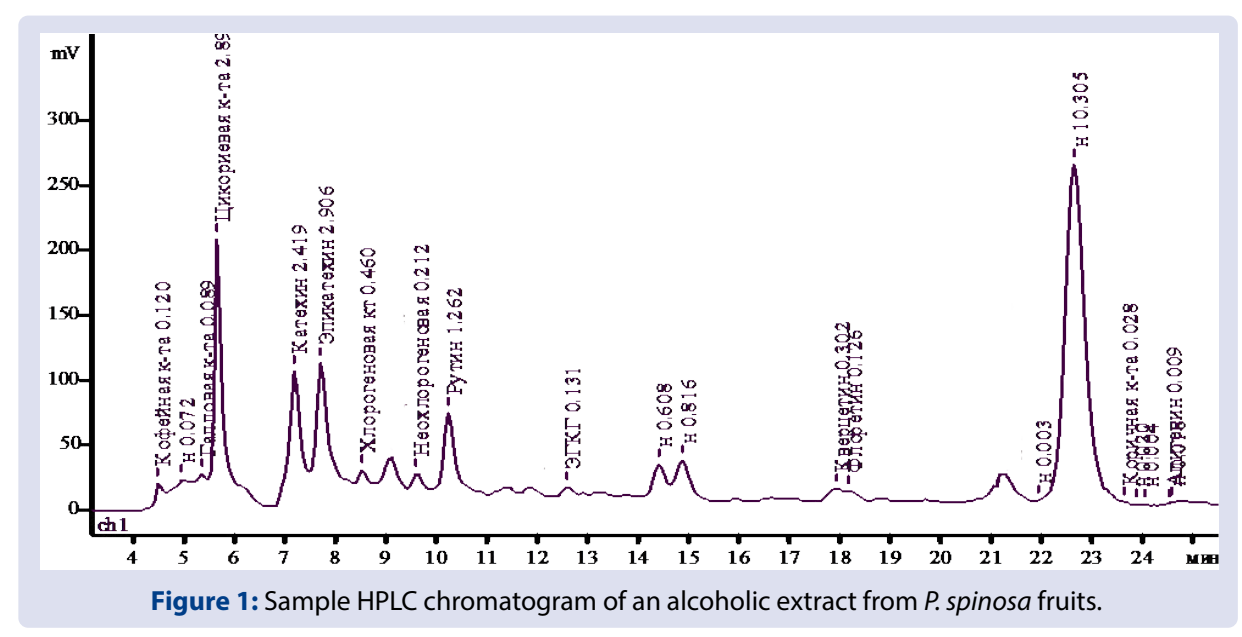


Table 1: Phenolic compounds of dried and fresh $P$. spinosa fruits.

\begin{tabular}{|c|c|c|c|c|}
\hline No. & Retention time, $\min$ & Area & Area, $\%$ & Compound \\
\hline 1 & 4.460 & 86.71 & 0.12 & Caffeic acid \\
\hline 2 & 4.895 & 52.11 & 0.07 & Unidentified \\
\hline 3 & 5.319 & 64.34 & 0.09 & Gallic acid \\
\hline 4 & 5.633 & 2088.28 & 2.90 & Chicoric acid \\
\hline 5 & 7.159 & 1741.89 & 2.42 & Catechin \\
\hline 6 & 7.690 & 2093.01 & 2.91 & Epicatechin \\
\hline 7 & 8.511 & 331.60 & 0.46 & Chlorogenic acid \\
\hline 8 & 9.073 & 582.90 & 0.81 & Unidentified \\
\hline 9 & 9.514 & 152.45 & 0.21 & Neochlorogenic acid \\
\hline 10 & 10.22 & 908.78 & 1.26 & Rutin \\
\hline 11 & 11.84 & 87.84 & 0.12 & Unidentified \\
\hline 12 & 12.56 & 94.00 & 0.13 & Epigallocatechin gallate \\
\hline 13 & 14.41 & 438.15 & 0.61 & Unidentified \\
\hline 14 & 14.86 & 588.03 & 0.82 & Unidentified \\
\hline 15 & 17.90 & 217.32 & 0.30 & Quercetin \\
\hline 16 & 18.21 & 90.67 & 0.13 & Unidentified \\
\hline 17 & 21.12 & 186.74 & 0.26 & Unidentified \\
\hline 18 & 21.27 & 262.50 & 0.36 & \\
\hline 19 & 21.38 & 205.58 & 0.29 & Unidentified \\
\hline 20 & 21.98 & 2.27 & 0.00 & Unidentified \\
\hline 21 & 22.63 & 7422.06 & 10.31 & Unidentified \\
\hline 22 & 23.65 & 19.94 & 0.03 & Cinnamic acid \\
\hline 23 & 23.86 & 14.28 & 0.02 & Unidentified \\
\hline 24 & 24.3 & 2.96 & 0.00 & Unidentified \\
\hline 25 & 24.51 & 6.54 & 0.01 & \\
\hline 26 & 24.59 & 12.90 & 0.02 & Unidentified \\
\hline 27 & 27.68 & 0.00 & 0.00 & Unidentified \\
\hline 28 & 28.74 & 25.73 & 0.04 & Unidentified \\
\hline 29 & 37.50 & 54243.52 & 75.31 & Unidentified \\
\hline
\end{tabular}

Table 2: THA content in P. spinosa fruits, expressed as chlorogenic acid.

\begin{tabular}{ccc}
\hline No. & Object, origin & THA, expressed as chlorogenic acid, \% \\
\hline 1 & Fresh fruits, Klinsky District of Moscow Region & $0.886 \pm 0.92$ \\
2 & Dried fruits, Klinsky District of Moscow Region & $0.540 \pm 0.71$ \\
3 & Fresh fruits, Chekhovsky District of Moscow Region & $0.798 \pm 0.89$ \\
4 & Dried fruits, Chekhovsky District of Moscow Region & $0.557 \pm 0.74$ \\
\hline
\end{tabular}

It is worth noticing that the THA content in dried fruits grown in Klinsky and Chehovsky Districts are similar $(0.540 \pm 0.71$ and 0.557 \pm 0.74 , respectively). However, despite the location of their growth, blackthorn fruits gathered to the south of Moscow (Chekhovsky District) had lower content of hydroxycinnamates, which may be attributed to natural variation in biologically active compounds content.

The results of the study confirm literature data on identification and quantitative assessment of hydroxycinnamic acids in different species of the Rosaceae family. Each plant has its own specific set of hydroxycinnamates. For example, coluria (Coluria geoides Pall.) contains gallic, $m$-coumaric, vanillic, and ellagic acids, ${ }^{15}$ cherry laurel (Prunus laurocerasus L.) - vanillic, protocatechuic, $p$-hydroxybenzoic, 3 4-dihydroxybenzoic, caffeic, $p$-coumaric, and cinnamic acids. ${ }^{16}$ Several kinds of hawthorn commonly contain neochlorogenic and chlorogenic acids, as well as caffeic and ferulic ones. ${ }^{17}$ Taking this variability into account, it is feasible to include chromatographic profiles of hydroxycinnamic acids in raw material specifications for both pharmaceutical and food industry, as it provides opportunity to identify even finely cut material and avoid misgrading.

\section{CONCLUSION}

It can be concluded that blackthorn fruits might be considered as a source of hydroxycinnamic acids - substances with promising pharmacological activity. Based on HPLC data, both fresh and dried fruits contain at least eleven hydroxycinnamates; some of the compounds remained unidentified, suggesting further in-depth research of their nature. Spectrophotometric analysis of THA content demonstrated that dried fruits have similar content of hydroxycinnamic acids, independently of their origin, and the growth location itself does not necessary convey information about higher or lower content of these substances. Future research should investigate various drying methods and conditions, in order to minimize the loss of biologically active substances and prolong shelf life.

\section{ACKNOWLEDGEMENTS}

Supported by the "Russian Academic Excellence Project 5-100".

\section{CONFLICTS OF INTEREST}

The authors declare no conflict of interests. 


\section{ABBREVIATIONS}

HPLC: High performance liquid chromatography; THA: Total hydroxycinnamic acids.

\section{REFERENCES}

1. Russian Plant Resources: wild flowering plants, their composition, and biological activity. Moscow: Fellowship of Scientific Publishers, 2009;205.

2. Aulus Cornelius Celsus. De medicina. Translation from Latin. Moscow, 1959.

3. Abu Ali Ibn Sino. The Canon of Medicine. Vol. 2. Uzbek SSR: FAN, 1994;619.

4. Kokh JA, Kokh DA. Fruits of prunus spinosa of krasnoyarsk krai-The perspective source for receiving biologically the active materials. Agricultural Journal in the Far East Federal District. 2017;1(41):57-60

5. Velickovic JM, Kostic DA, Stojanovic GS, Mitic SS, Radelovic SS, Dordevic AS. Phenolic composition, antioxidant and antimicrobial activity of extracts from Prunus spinose L. fruit. Hemijska Industrija. 2014;68(3):297-303.

6. Wolbis M, Olszewska M, Welowski W. Triterpens and sterols in the flowers and leaves of Prunus spinose L. (Rosaceae). Acta Poloniae Pharmaceutica. $2001 ; 58(6): 459-62$.

7. Safonova IA, Yatzuk VY, Fatyanov AA, Safonov AA. Studiyng of elemental composition of Prunus spinosa (L.) fruits and leaves. Belgorod State University Scientific Bulletin. Medicine Pharmacy. 2011;4(13):165-9.

8. Kumarasamy Y, Cox PJ, Jasparrs M, Nahar L, Sarker SD. Comparative studies on biological activities of Prunus padus and P. spinosa. Fitoterapia. 2004;75(1):77-80.
9. Herald PJ, Davidson PM. Antibacterial activity of selected hydroxycinnamic acids. Journal of Food Science. 1983;48(4):1378-9.

10. Meyer AS, Donovan JL, Pearson DA, Waterhouse AL, Frankel EN. Fruit hydroxycinnamic acids inhibit human low-density lipoprotein oxidation in vitro. Journal of Agricultural and Food Chemistry. 1998;46(5):1783-7.

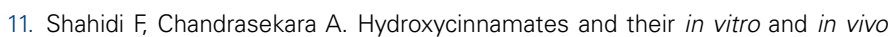
antioxidant activities. Phytochemistry Reviews. 2010;9(1):147-70.

12. Ferguson LR, Zhu ST, Harris PJ. Antioxidant and antigenotoxic effects of plant cell wall hydroxycinnamic acids in cultured HT-29 cells. Molecular Nutrition \& Food Research. 2005;49(6):585-93.

13. Rocha LD, Monteiro MC, Teodoro AJ. Anticancer properties of hydroxycinnamic acids - A Review. Cancer and Clinical Oncology. 2012;1(2):109-21.

14. Deineka VI, Khlebnikov VA, Sorokopudov VN, Anisimovich IP. Chlorogenic acid in fruits and leaves of some plants in the Berberidaceae family. Chemistry of Natural Compounds. 2008;1:57-61.

15. Myadelets MA, Dutova SV. A comparative assessment of phenolics composition of Coluria geoides (Rosaceae) dry extract. Proceedings of IX International Symposium "Phenolic compounds: fundamental and applied aspects". 2015. Moscow, Russia.

16. Ayaz FA, Reumanen M, Var M. Determination of carboxylic acids in the fruits of Laurocerasus officinalis Roem. and its cultivars. ChemInform. 1999;10(18):10836.

17. Goncharov NF, Mihailov IV, Goncharov NN. Hydroxycinnamic acids in flowers and leaves of non-pharmacopoeial hawthorn species. Fundamental Studies. 2011:9(1):146-8.

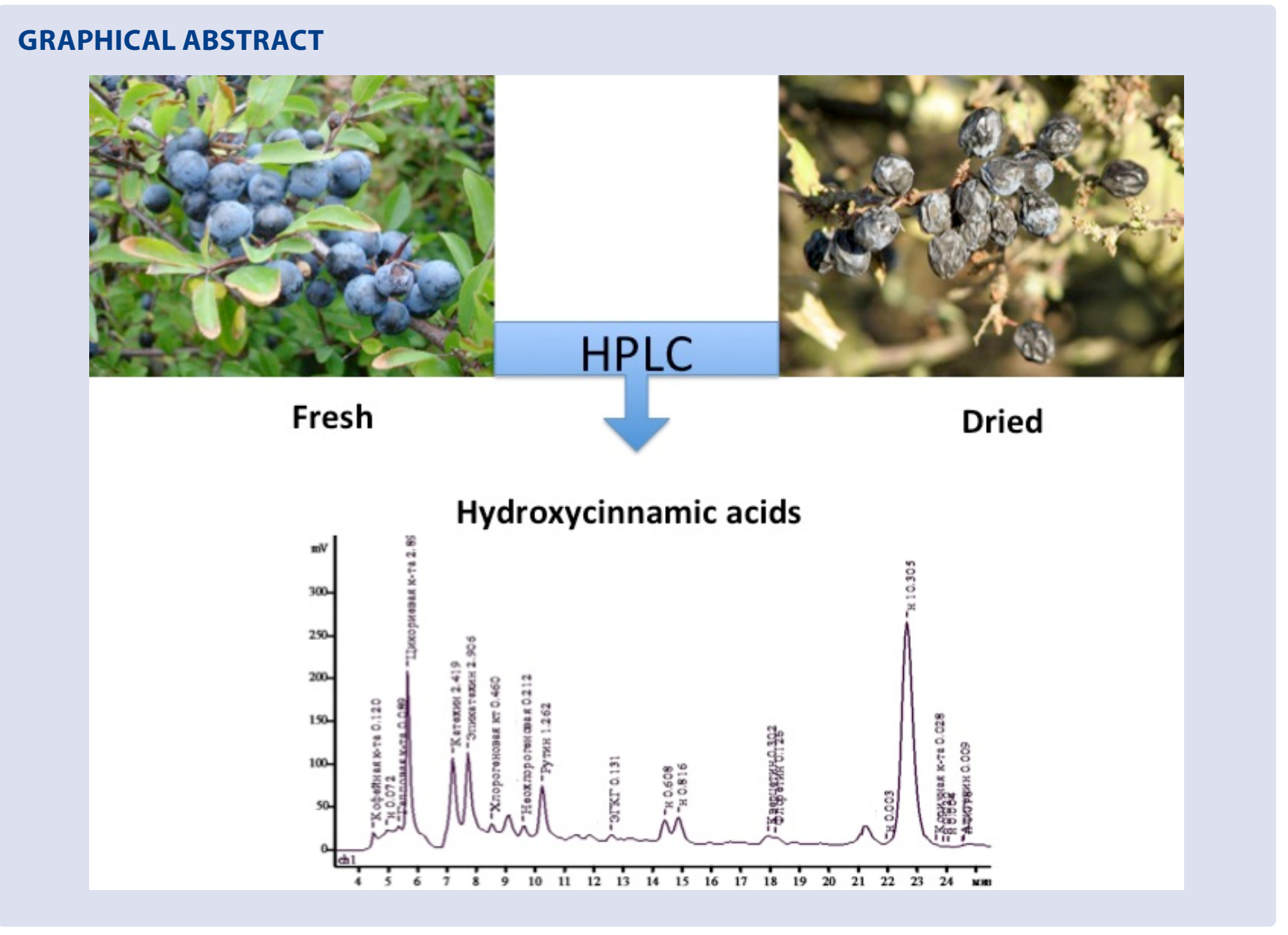




\section{ABOUT AUTHORS}

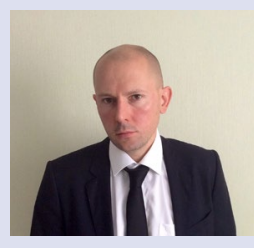

Sergey V. Kondrashev graduated from Pharmaceutical Faculty of the Sechenov First Moscow State Medical Academy in 1996, earned his PhD degree in 1999, and is currently working as the Associate Professor of the Department of Chemistry of the Institute of Pharmacy. His scientific interests are focused on standardization of herbal raw material and phytodrugs.

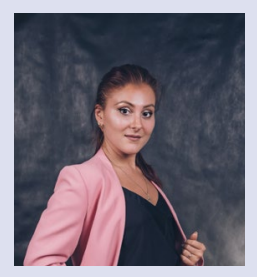

Nadezhda V. Nesterova, Assistant Professor of the Department of Natural Sciences in Pharmacy, graduated from Pharmaceutical Faculty of the Sechenov First Moscow State Medical University in 2015, finished her $\mathrm{PhD}$ research in 2018, and earned PhD degree in 2019. Her research is focused on standardization of herbal raw material and phytodrugs.

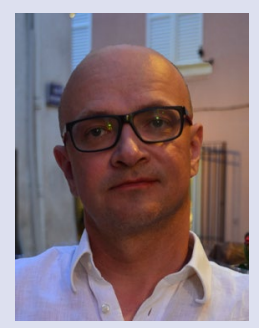

Alexey A. Luzin, PhD, graduated from the Department of Chemistry of the Moscow State University and currently working as the Associate Professor of the Department of Chemistry of the Institute of Pharmacy. His scientific interests include drug and dental materials standardization, and characterization of high molecular weight compounds.

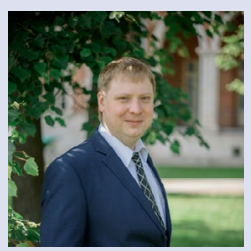

Vitaliy S. Kochanov graduated from the Pharmaceutical Faculty of the Sechenov First Moscow State Medical Academy and is currently working as the Assistant Professor of the Department of Chemistry of the Institute of Pharmacy. His scientific work is focused on studying novel sources of biologically active substances

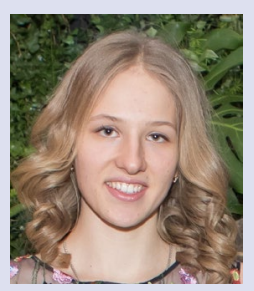

Anna V. Luzina is a 5 th year student of the Institute of Dentistry. Her research is focused on standardization of dental materials, materials science, dental orthopedics, and gnathology.

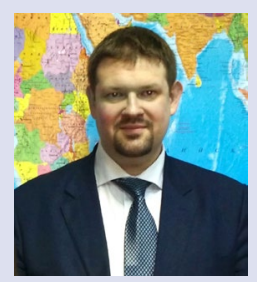

Alexey A. Matyushin graduated from Pharmaceutical Faculty of the Sechenov First Moscow State Medical Academy in 2008, earned his PhD degree in 2011, and MA degree - in 2018. Currently he's working as the Associate Professor of the Department of Analytical and Forensic Toxicology. His main scientific interests are focused on identification and standardization of novel herbal drugs and herbal raw materials, separation and purification of biologically active substances from natural sources, and herbal drugs development.

Cite this article: Kondrashev S, Nesterova N, Luzin A, Kochanov V, Luzina A, Matyushin A. Qualitative and Quantitative Assay of Hydroxycinnamates of Prunus Spinosa L. Pharmacog J. 2020;12(1):157-61. 